\title{
Cardiovascular Risk Factor Profile of Unstable angina patients in Bangladesh
}

\section{MA Siddique, MA Sultan, MA Rahman, T Parvin, AA Jamil, KMAS S Haque}

\section{Background:}

In recent years, unstable angina has emerged as a dominant cause of hospital Admission.

\section{Purpose:}

To observe the cardiovascular risk factors in patients with unstable angina,

\section{Methods:}

Observational study with 205 patients of diagnosed unstable angina who were admitted between January 2002 to June 2003 in cardiology department of Bangabandhu Sheikh Mujib medical University.

\section{Results:}

Out of 205 cases 167 (75\%) were male, 40 (25\%) were female with a mean age of $54.82 \pm 11.72$ (age range 24-90 years). Among 205 cases 85 (41\%) had hypertension, 62 (30\%) had dyslipidaemia, 53 (26\%) were smoker, 50 (24\%) were diabetic, 27 (13\%) had left ventricular hypertrophy, $25(12 \%)$ had positive family history of ischaemic heart disease and $10(5 \%)$ were obese.

\section{Conclusion:}

High prevalence of multiple cardiovascular risk factors superadded by a tendency for aggregation of risk factors in the same individual explains the recent increase in occurrence of unstable angina in Bangladesh. 